\title{
Improve Roll Dynamic Response of Road Vehicle to Step Steer Input using Semi-active PID Suspension Controller
}

\author{
Karim H. Ali, PhD \\ University of Baghdad \\ College of Engineering \\ Mechanical Department
}

\author{
Farah Ayad A. Majeed \\ University of Baghdad \\ College of Engineering \\ Mechanical Department
}

\begin{abstract}
Roll dynamic response is investigated and studied to improve the dynamic behavior of road vehicle during sudden maneuver according to step steer input using semi-active PID suspension. A Mathematical model including the differential governing equations of operation for full road vehicle with (9) degrees of freedom and passive PID suspension is presented. Car body movements and displacements are investigated using Computer-aided simulation with Matlab Program for different vehicle speeds and specified step steer angles. A special technique is used to transform the second order differential equations of operation for the road vehicle into first order equations in order to reduce the computational time. Simulation results shows the dynamic responses of road vehicle at vertical, pitch and roll motions subjected to different vehicle speeds and step steer angles utilizing settling time and maximum peak overshoot, also the results show an improvement in dynamic roll response using semi-active PID suspension with conical shaped spring.
\end{abstract}

\section{Keywords}

Roll dynamic response, Semi active suspension, PID controller, road vehicle

\section{INTRODUCTION}

Ride passenger comfort and safety are the most important parameters should be considered when transportation equipment and devices are utilized. Road vehicle is widely used these days to transport passengers for long distances subjected to different external road conditions. Undesirable vibrations and oscillations may be introduced according to these external road disturbances by which many mechanical problems will occur that cause unsafely road vehicle handling with ride passenger discomfort. Hence road vehicle should be subjected to some control devices such as braking control, traction control, acceleration control, lateral stability control and suspension control. Such road vehicle control systems refer to enhance ride passenger comfort with safety road vehicle handling. Suspension with PID semi-active controller is used in this study to improve vehicle dynamic response based on roll movement.

Suspensions are considered as an important control elements widely used in most vehicle applications and vibrating machinery such as cars and trains used to depress vibrations and oscillations introduced throughout dynamic running. Whereas these suspensions are the most important control element used to satisfy ride passenger comfort and safety. In a classical car suspension which is commonly called passive PID suspension, it aims to achieve isolation from the road disturbances by means of spring-type elements and viscous dampers (shock absorbers).
Many studies have been accomplished to improve road vehicle dynamic response using different suspension PID controllers in order to achieve ride passenger comfort and safety.

M. Senthil Kumar et al. [2007] describes the development of active suspension system of light passenger vehicle to improve ride comfort of the passengers using PID (Proportional -Integral -Derivative) controller. The system is subjected to bumpy road and its performance is assessed and compared with a passive suspension system. Experimental verification of analytical results is carried out. It is found that ride comfort is improved by $78.03 \%$, suspension travel has been reduced by $71.05 \%$ an $\mathrm{d}$ road holding ability is improved by $60 \%$ with active suspension system when compared with passive suspension system. The study of Anil Shirahatt et al. [2008] shows a suitable optimizing technique at design stage to obtain the suspension parameters of a passive suspension and active suspension for a passenger car. The constraints arise from the practical kinetic and comfortability considerations, such as limits of the maximum vertical acceleration of the passenger seat, tyre displacement and the suspension working space. Results show passenger bounce, passenger acceleration, and tyre displacement are reduced by $74.2 \%, 88.72 \%$ and $28.5 \%$ respectively. In the study of $\mathbf{M}$. Zapateiro et al. [2009] the problem of designing the semiactive controller for a class of vehicle suspension system is investigated. As the first step, an adequate model of the MR damper must be developed. Estimate the control voltage input to the MR damper, which is necessary for producing the optimal force predicted by the controller so as to reduce the vibrations. The performance of the control system is evaluated bymeans of simulations in MATLAB/Simulink.

Bushra Rasheed Mohameed [2011] describes a unique solution of bouncing and pitching interactions, in which it play an increasingly significant role in vehicle. This work is theoretical and finite element method via ANSYS software study of dynamic performance of vehicle. Przemyslaw Gorczyca et al. [2011] is concerned with a mathematical model of the semi-active suspension system of a vehicle modeled with a car quarter while a simulation model is written by in the Matlab/Similink program. The research of Soud farhan Choudhury et al. [2012] is carried out to study the performance of two basic suspension systems with a different approach, passive and active suspension system. For the simplicity, mathematical modeling is done by assuming 2 degree of freedom (2 DOF) system. Quarter car model is used to simplify the system. To analyze the model, simulation software MATLAB/SIMULINK is used. M. Khairi et al. [2013] presents the composite nonlinear feedback (CNF) technique for yaw tracking control of active front steering system with the objectives to improve the transient performance of yaw rate response. For lateral and yaw 
dynamics analysis, nonlinear and linear vehicle models are utilized as actual vehicle plant and for controller design respectively. The simulation results demonstrate that the application of CNF for yaw rate tracking control improves the yaw stability and vehicle handling Performances.

Ali M. Abd-El- Tawwab [2013] stated that semi-active suspension system is a possible way to improve suspension performance although the passive system can effectively handle some control of suspension system. The main propose is to assess performance of semi-active suspension system by implementing Fuzzy and Proportional-Integral-Derivative (PID) controls in comparison with passive suspension system. The performance of pneumatic semi-active suspension system theoretically and experimentally predicted using two degrees of freedom of quarter car model. The results showed that there is a worthwhile improvement for the pneumatic semi-active suspension system with fuzzy control over the passive. The study of Devdut et al. [2014] presents different semi-active control strategies for non-linear quarter car model equipped with controllable magneto-rheological (MR) shock absorbers. Simulink responses of four different cases are evaluated for passenger ride comfort analysis taking uncontrolled, primary suspension controlled, secondary suspension controlled and fully controlled quarter car models. The obtained results in graphical and mathematical form demonstrate that the fully controlled

quarter car system provides excellent performance in suppression of passenger seat vibrations compared to other control strategies while the vehicle travels over the sinusoidal type of input road profile.

Through the reviewed literature, it was addressed that many dynamic problems occur in road vehicle system during operation, such as hunting instability, damage into mechanical components, excessive vehicle vibrations, and prospective ride passenger discomfort. Thus the significance of this research is to introduce the parameters that have an important influence on the dynamic behavior of the vehicle system. In which these parameters are controlled to eliminate the introduced mechanical problems.

\section{FULL VEHICLE MATEMATICAL MODEL}

Road vehicle is modeled with (9) degrees of freedom including vertical displacement of the carbody and for the front and rear wheels. Also roll, pitch, yaw and lateral movements for the carbody is constructed as shown in Figure 1.

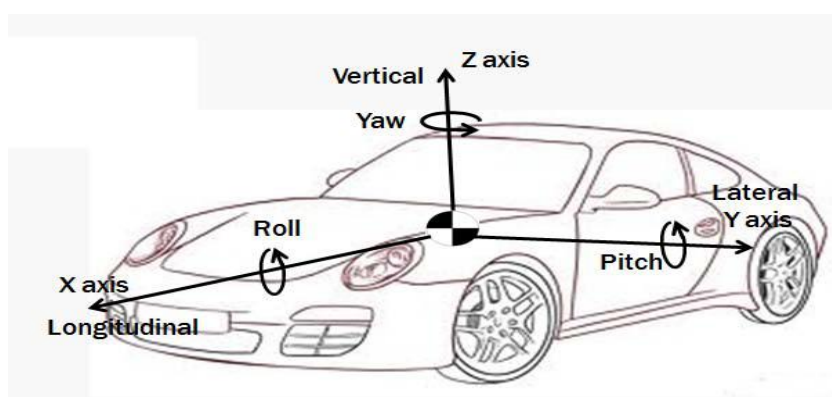

Fig 1: Road vehicle displacements

Mathematical differential equations of operation for the road vehicle expressing vertical, roll, and pitch are derived as in the following equations as shown in Figure 2.

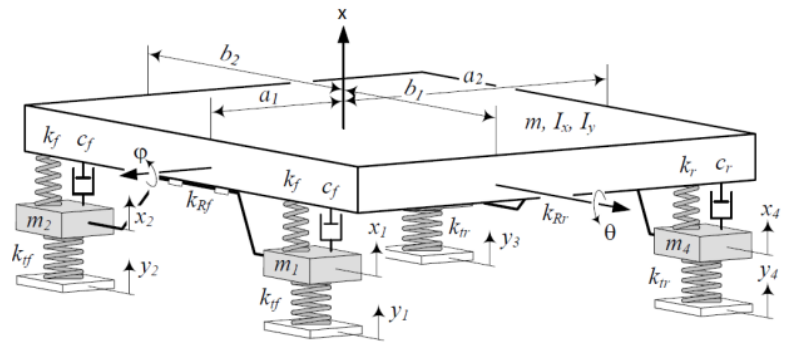

Fig 2: Full road vehicle vibration model

The equation of the vertical displacement of car body is:

$$
\begin{aligned}
\mathrm{mZ}=-2\left(\mathrm{C}_{\mathrm{f}}+\mathrm{C}_{\mathrm{r}}\right) \dot{\mathrm{Z}} & +\mathrm{C}_{\mathrm{f}} \dot{\mathrm{Z}}_{\mathrm{w} 1}+\mathrm{C}_{\mathrm{f}} \dot{\mathrm{Z}}_{\mathrm{w} 2}+\mathrm{C}_{\mathrm{r}} \dot{\mathrm{Z}}_{\mathrm{w} 3}+\mathrm{C}_{\mathrm{r}} \dot{\mathrm{Z}}_{\mathrm{w} 4} \\
& +\left(-\mathrm{b}_{1}+\mathrm{b}_{2}\right)\left(\mathrm{C}_{\mathrm{f}}+\mathrm{C}_{\mathrm{r}}\right) \dot{\emptyset} \\
& +2\left(\mathrm{C}_{\mathrm{f}} \mathrm{a}_{1}-\mathrm{C}_{\mathrm{r}} \mathrm{la}_{2}\right) \dot{\theta}-2\left(\mathrm{~K}_{\mathrm{f}}+\mathrm{K}_{\mathrm{r}}\right) \mathrm{Z} \\
& +\mathrm{K}_{\mathrm{f}} \mathrm{Z}_{\mathrm{w} 1}+\mathrm{K}_{\mathrm{f}} \mathrm{Z}_{\mathrm{w} 2}+\mathrm{K}_{\mathrm{r}} \mathrm{Z}_{\mathrm{w} 3}+\mathrm{K}_{\mathrm{r}} \mathrm{Z}_{\mathrm{w} 4} \\
& +\left(-\mathrm{b}_{1}+\mathrm{b}_{2}\right)\left(\mathrm{K}_{\mathrm{f}}+\mathrm{K}_{\mathrm{r}}\right) \emptyset \\
& +2\left(\mathrm{~K}_{\mathrm{f}} \mathrm{a}_{1}-\mathrm{K}_{\mathrm{r}} \mathrm{a}_{2}\right) \theta
\end{aligned}
$$

While equation of the vertical displacements of front and rear wheels are:

$$
\begin{aligned}
& \mathrm{m}_{\mathrm{w}} \ddot{\mathrm{Z}}_{\mathrm{w} 1}=\mathrm{C}_{\mathrm{f}} \dot{\mathrm{Z}}-\mathrm{C}_{\mathrm{f}} \dot{\mathrm{Z}}_{\mathrm{w} 1}+\mathrm{C}_{\mathrm{f}} \mathrm{b}_{1} \dot{\emptyset}-\mathrm{C}_{\mathrm{f}} \mathrm{a}_{1} \dot{\theta}+\mathrm{K}_{\mathrm{f}} \mathrm{Z} \\
& +\left(\mathrm{K}_{\mathrm{f}}-\mathrm{K}_{\mathrm{rf}} \frac{1}{\left(\mathrm{~b}_{1}+\mathrm{b}_{2}\right)^{2}}-\mathrm{K}_{\mathrm{tf}}\right) \mathrm{Z}_{\mathrm{w} 1} \\
& +\left(\mathrm{K}_{\mathrm{f}} \mathrm{b}_{1}+\mathrm{K}_{\mathrm{rf}} \frac{1}{\mathrm{~b}_{1}+\mathrm{b}_{2}}\right) \varnothing-\mathrm{K}_{\mathrm{f}} \mathrm{a}_{1} \theta \\
& +\mathrm{K}_{\mathrm{rf}} \frac{\mathrm{Z}_{\mathrm{w} 2}}{\left(\mathrm{~b}_{1}+\mathrm{b}_{2}\right)^{2}}+\mathrm{K}_{\mathrm{tf}} \mathrm{Z}_{\mathrm{w} 1} \\
& \mathrm{~m}_{\mathrm{w}} \ddot{\mathrm{Z}}_{\mathrm{w} 2}=\mathrm{C}_{\mathrm{f}} \dot{\mathrm{Z}}-\mathrm{C}_{\mathrm{f}} \dot{\mathrm{Z}}_{\mathrm{w} 2}-\mathrm{C}_{\mathrm{f}} \mathrm{b}_{2} \dot{\varnothing}-\mathrm{C}_{\mathrm{f}} \mathrm{a}_{1} \dot{\theta}+\mathrm{K}_{\mathrm{f}} \mathrm{Z} \\
& -\left(\mathrm{K}_{\mathrm{f}}-\mathrm{K}_{\mathrm{rf}} \frac{1}{\left(\mathrm{~b}_{1}+\mathrm{b}_{2}\right)^{2}}-\mathrm{K}_{\mathrm{tf}}\right) \mathrm{Z}_{\mathrm{w} 2} \\
& -\left(\mathrm{K}_{\mathrm{f}} \mathrm{b}_{2}+\mathrm{K}_{\mathrm{rf}} \frac{1}{\mathrm{~b}_{1}+\mathrm{b}_{2}}\right) \varnothing-\mathrm{K}_{\mathrm{f}} \mathrm{a}_{1} \theta \\
& +\mathrm{K}_{\mathrm{rf}} \frac{\mathrm{Z}_{\mathrm{w} 2}}{\left(\mathrm{~b}_{1}+\mathrm{b}_{2}\right)^{2}}+\mathrm{K}_{\mathrm{tf}} \mathrm{Z}_{\mathrm{w} 2} \\
& \mathrm{~m}_{\mathrm{w}} \ddot{\mathrm{Z}}_{\mathrm{w} 3}=\mathrm{C}_{\mathrm{f}} \dot{\mathrm{Z}}-\mathrm{C}_{\mathrm{f}} \dot{\mathrm{Z}}_{\mathrm{w} 3}+\mathrm{C}_{\mathrm{r}} \mathrm{b}_{1} \dot{\emptyset}+\mathrm{C}_{\mathrm{r}} \mathrm{a}_{2} \dot{\theta}+\mathrm{K}_{\mathrm{r}} \mathrm{Z} \\
& -\left(K_{r}+K_{r r} \frac{1}{\left(b_{1}+b_{2}\right)^{2}}+K_{t f}\right) Z_{w 3} \\
& +\left(\mathrm{K}_{\mathrm{r}} \mathrm{b}_{1}+\mathrm{K}_{\mathrm{rr}} \frac{1}{\mathrm{~b}_{1}+\mathrm{b}_{2}}\right) \varnothing+\mathrm{K}_{\mathrm{r}} \mathrm{a}_{2} \theta \\
& +\mathrm{K}_{\mathrm{rr}} \frac{\mathrm{Z}_{\mathrm{w} 3}}{\left(\mathrm{~b}_{1}+\mathrm{b}_{2}\right)^{2}}+\mathrm{K}_{\mathrm{tr}} \mathrm{Z}_{\mathrm{w} 3} \\
& \mathrm{~m}_{\mathrm{w}} \ddot{\mathrm{Z}}_{\mathrm{w} 4}=\mathrm{C}_{\mathrm{f}} \dot{\mathrm{Z}}-\mathrm{C}_{\mathrm{f}} \dot{\mathrm{Z}}_{\mathrm{w} 4}-\mathrm{C}_{\mathrm{r}} \mathrm{b}_{2} \dot{\emptyset}+\mathrm{C}_{\mathrm{r}} \mathrm{a}_{2} \dot{\theta}+\mathrm{K}_{\mathrm{r}} \mathrm{Z} \\
& -\left(K_{r}+K_{r r} \frac{1}{\left(b_{1}+b_{2}\right)^{2}}+K_{t f}\right) Z_{w 4} \\
& -\left(\mathrm{K}_{\mathrm{r}} \mathrm{b}_{2}+\mathrm{K}_{\mathrm{rr}} \frac{1}{\mathrm{~b}_{1}+\mathrm{b}_{2}}\right) \emptyset+\mathrm{K}_{\mathrm{r}} \mathrm{a}_{2} \theta \\
& +\mathrm{K}_{\mathrm{rr}} \frac{\mathrm{Z}_{\mathrm{w} 4}}{\left(\mathrm{~b}_{1}+\mathrm{b}_{2}\right)^{2}}+\mathrm{K}_{\mathrm{tr}} \mathrm{Z}_{\mathrm{w} 4}
\end{aligned}
$$

The equation of roll angular displacements for the carbody are constructed as the following equations,

$$
\begin{aligned}
& I_{x x} \ddot{\emptyset}=-\left[\left(b_{1}-b_{2}\right)\left(C_{f}-C_{r}\right)\right] \dot{Z}+b_{1} C_{f} \dot{Z}_{w 1}-b_{2} C_{f} \dot{Z}_{w 2}- \\
& b_{1} C_{r} \dot{Z}_{w 3}+b_{2} C_{r} \dot{Z}_{w 4}-\left[\left(b_{1}^{2}+b_{2}^{2}\right)\left(C_{f}-C_{r}\right)\right] \dot{\varnothing}+ \\
& {\left[\left(a_{1} b_{1}-a_{1} b_{2}\right) C_{f}+\left(a_{2} b_{1}-a_{2} b_{2}\right) C_{r}\right] \dot{\theta}-\left[( b _ { 1 } - b _ { 2 } ) \left(K_{f}-\right.\right.} \\
& \left.\left.K_{r}\right)\right] Z+b_{1} K_{f} Z_{w 1}-b_{2} K_{f} Z_{w 2}-b_{1} K_{r} Z_{w 3}+b_{2} K_{r} Z_{w 4}- \\
& {\left[\left(b_{1}^{2}+b_{2}^{2}\right)\left(K_{f}-K_{r}\right)\right] \emptyset+\left[\left(a_{1} b_{1}-a_{1} b_{2}\right) K_{f}+\left(a_{2} b_{1}-\right.\right.} \\
& \left.\left.a_{2} b_{2}\right) K_{r}\right] \theta
\end{aligned}
$$

Whereas the equation of pitch angular displacements for the carbody are constructed as the following equations, 


$$
\begin{aligned}
I_{y y} \ddot{\theta}=2\left(a_{1} C_{f}-\right. & \left.a_{2} C_{r}\right) \dot{Z}-a_{1} C_{f} \dot{Z}_{w 1}-a_{1} C_{f} \dot{Z}_{w 2}+a_{2} C_{r} \dot{Z}_{w 3} \\
& +a_{2} C_{r} \dot{Z}_{w 4} \\
& +\left[\left(a_{1} b_{1}-a_{1} b_{2}\right) C_{f}\right. \\
& \left.-\left(a_{2} b_{1}-a_{2} b_{2}\right) C_{r}\right] \dot{\emptyset} \\
& -2\left(a_{1}^{2} C_{f}+a_{2}^{2} C_{r}\right) \dot{\theta}+2\left(a_{1} K_{f}-a_{2} K_{r}\right) Z \\
& -a_{1} K_{f} Z_{w 1}-a_{1} K_{f} Z_{w 2}+a_{2} K_{r} Z_{w 3} \\
& +a_{2} K_{r} Z_{w 4} \\
& +\left[\left(a_{1} b_{1}-a_{1} b_{2}\right) K_{f}\right. \\
& \left.-\left(a_{2} b_{1}-a_{2} b_{2}\right) K_{r}\right] \varnothing \\
& -2\left(a_{1}^{2} K_{f}+a_{2}^{2} K_{r}\right) \theta
\end{aligned}
$$

Yaw and lateral motion for the carbody are constructed as the following equations as shown in Figure 3,

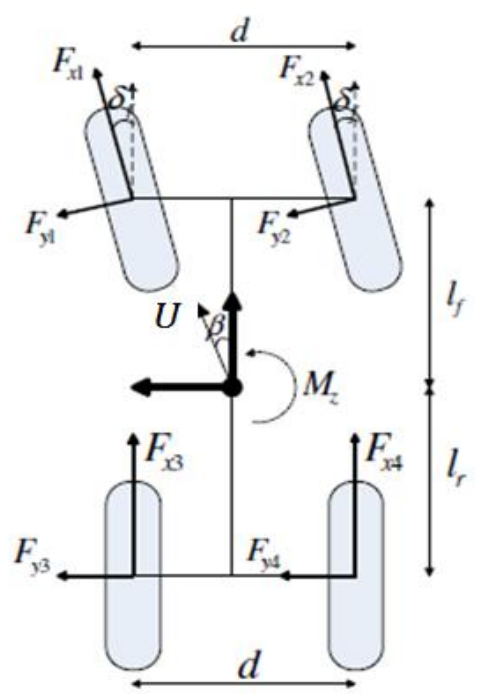

Fig 3: Yaw and lateral motion for road vehicle

Yaw motion of the car body can be expressed by the following:

$$
\begin{aligned}
I_{z z} \ddot{\psi}=2 l_{f} C_{f} \delta \cos \delta & -\left(\frac{2 l_{f} C_{f}}{U} \cos \delta\right) \dot{Y}-\left(2 l_{f}^{2} \frac{C_{f}}{U} \cos \delta\right) \dot{\psi} \\
& +2 l_{r} \frac{C_{r}}{U} Y-2 l_{r}^{2} \frac{C_{r}}{U} \dot{\psi} \\
& +2 \mu g l_{f}\left(\frac{m_{t}}{4}+m_{w}\right) \sin \delta
\end{aligned}
$$

The lateral motion of the car body can be written as:

$$
\begin{aligned}
m_{t} \ddot{Y}=2 C_{f} \delta \cos \delta & -\left(\frac{2 C_{f}}{U} \cos \delta\right) \dot{Y}-\left(2 \frac{C_{f}}{U} l_{f} \cos \delta\right) \dot{\psi} \\
& -2 \frac{C_{r}}{U} \dot{Y}+2 \frac{C_{r}}{U} l_{r} \dot{\psi} \\
& +2 \mu g\left(\frac{m_{t}}{4}+m_{w}\right) \sin \delta+U \dot{\psi}
\end{aligned}
$$

\section{ROAD VEHICLE SIMULATION MODEL}

Computer-adid simulation is presented to investigate the vehicle dynamic response subjected to different vehicle speeds a7nd sudden steer angles while the mathematical differential equations of operation for the full road vehicle are transformed into first order differential equations in order to reduce computational time. Figures below show that roll dynamic response is more sensitive to any change in vehicle speeds and sudden step steer angles.
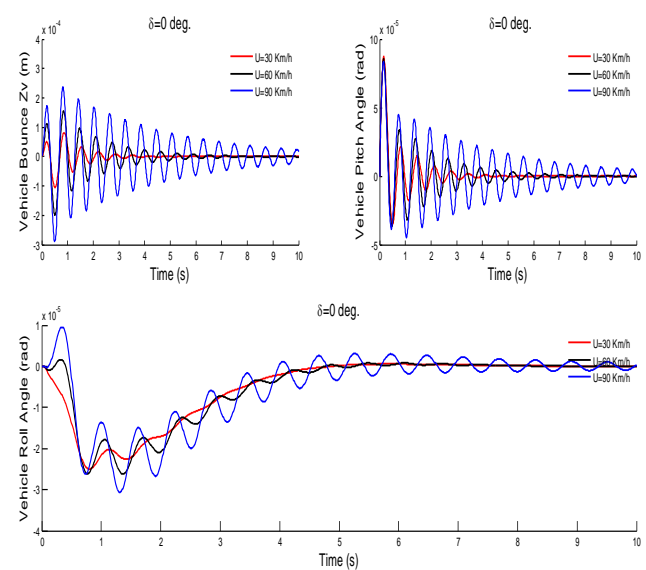

Fig 4: Vertical, pitch and roll responses of road vehicle car body subjected to different speeds with 0 steer angle
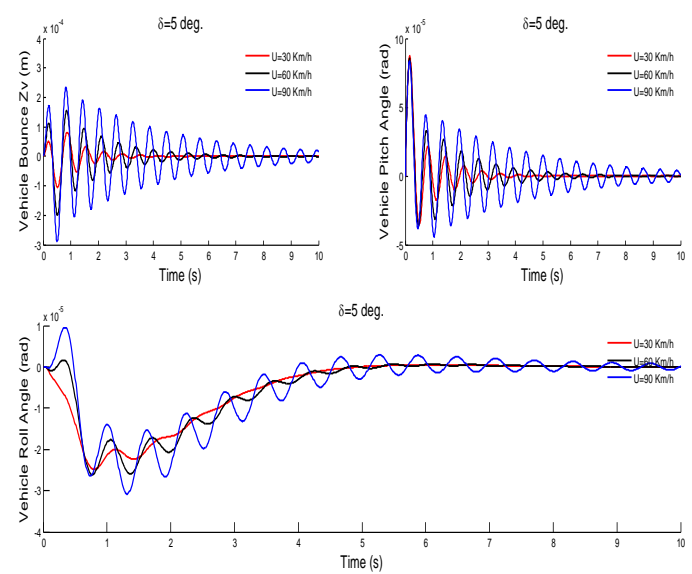

Fig 5: Vertical, pitch and roll responses of road vehicle car body subjected to different speeds with 5 steer angle
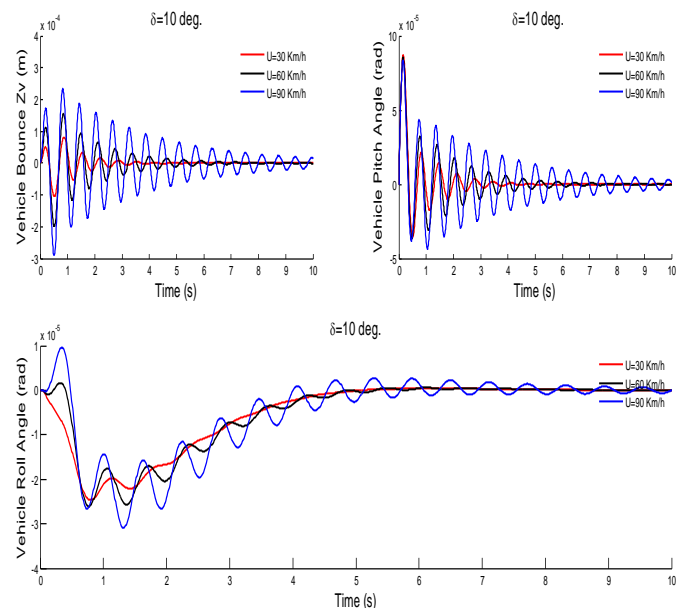

Fig 6: Vertical, pitch and roll responses of road vehicle car body subjected to different speeds with 10 steer angle and passive PID suspension controller 

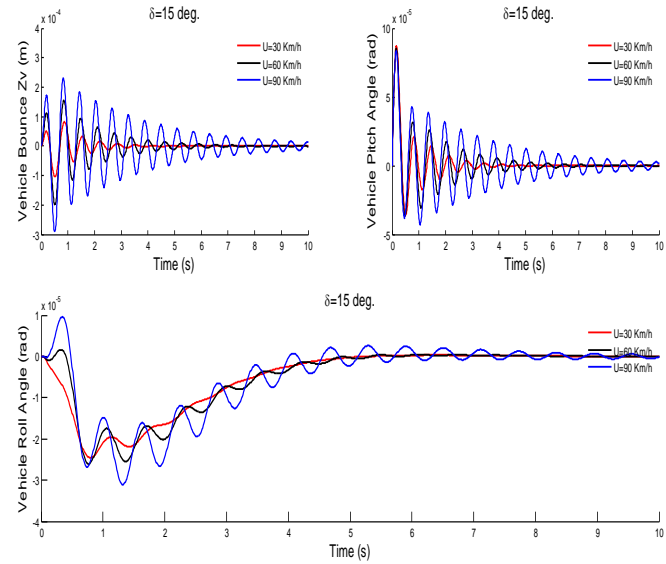

Fig 7: Vertical, pitch and roll responses of road vehicle car body subjected to different speeds with 10 steer angle and passive PID suspension controller

\section{ANALYSIS OF ROAD VEHICLE SIMULATION RESULTS}

The vertical, pitch and roll responses of car body that are included from simulation results are investigated and analyzed to represent the most sensitive parameter to change in road vehicle speeds and sudden step steer angles. Specifications for settling time and maximum peak overshoot are adapted to investigate and study the behavior of vertical, pitch and roll motions of the road vehicle car body. A comparison is performed between the behavior of vertical, pitch and roll motion of the road vehicle car body. A comparison is performed between the behaviors of these three motions in which shows the roll dynamic response of road vehicle is the parameter that should be used as a threshold to improve the overall response of the road vehicle to any sudden external disturbances.

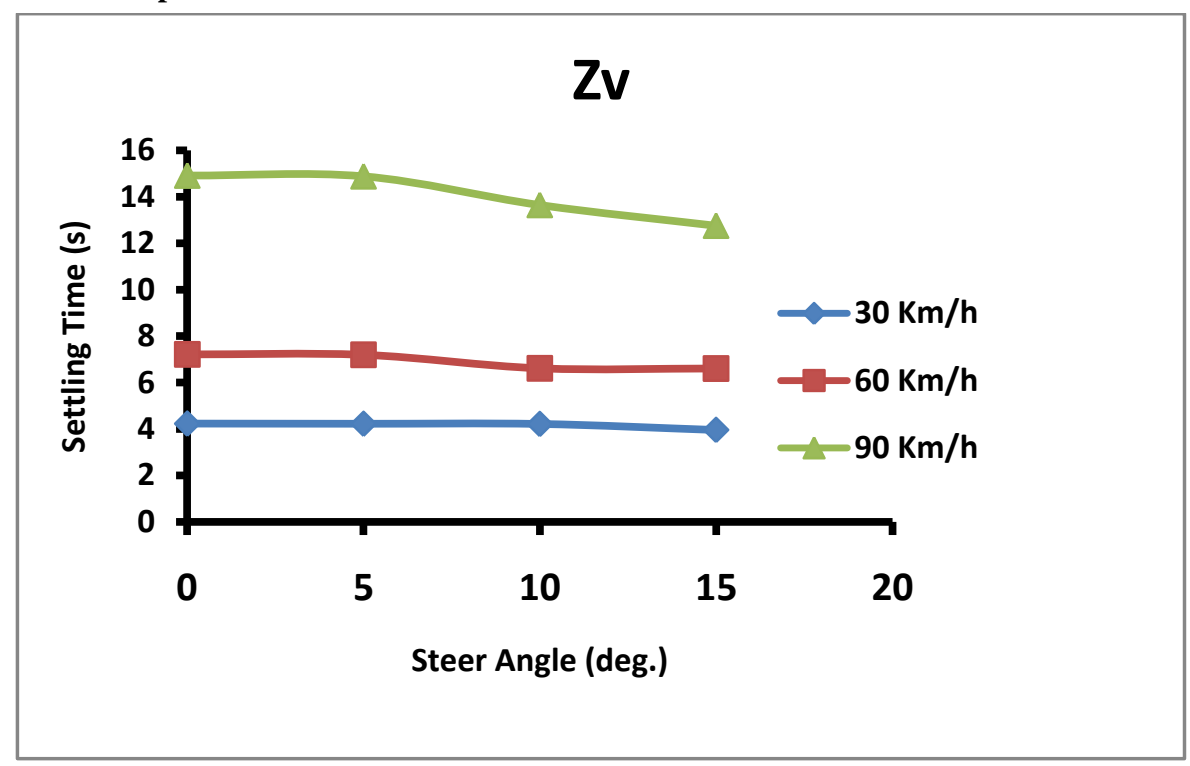

Fig 8: Settling time analysis for road vehicle Vertical response subjected to different vehicle speeds and steer angle

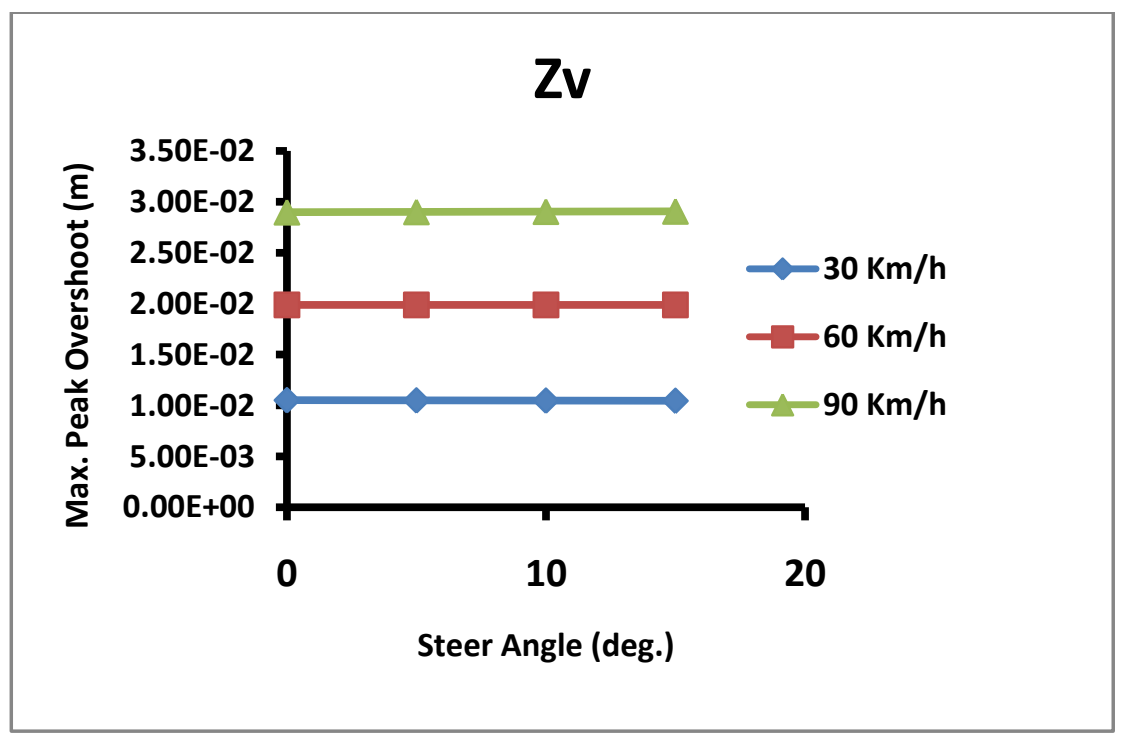

Fig 9: Maximum Peak overshoot analysis for road vehicle Vertical response subjected to different vehicle speeds and steer angle 


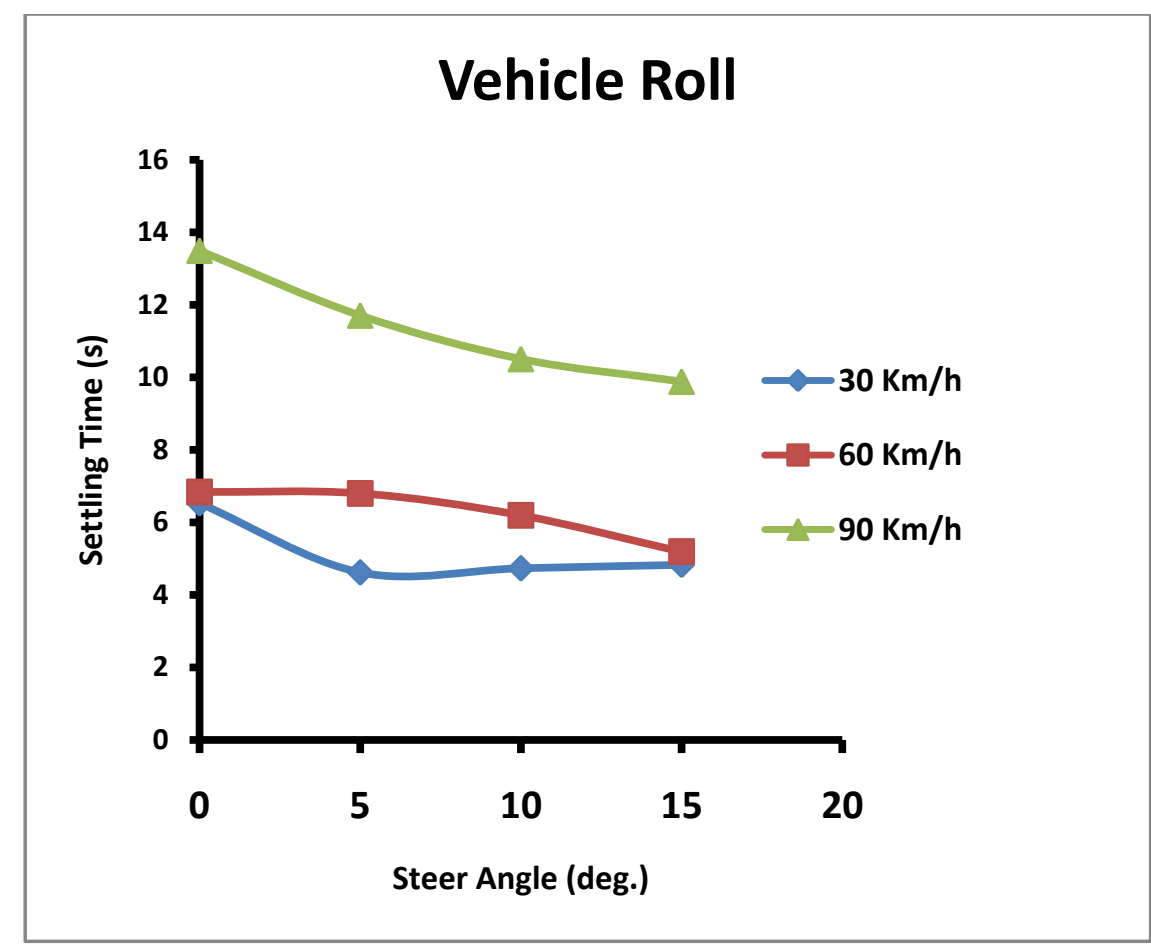

Fig 10: Settling time analysis for road vehicle roll response subjected to different vehicle speeds and steer angle

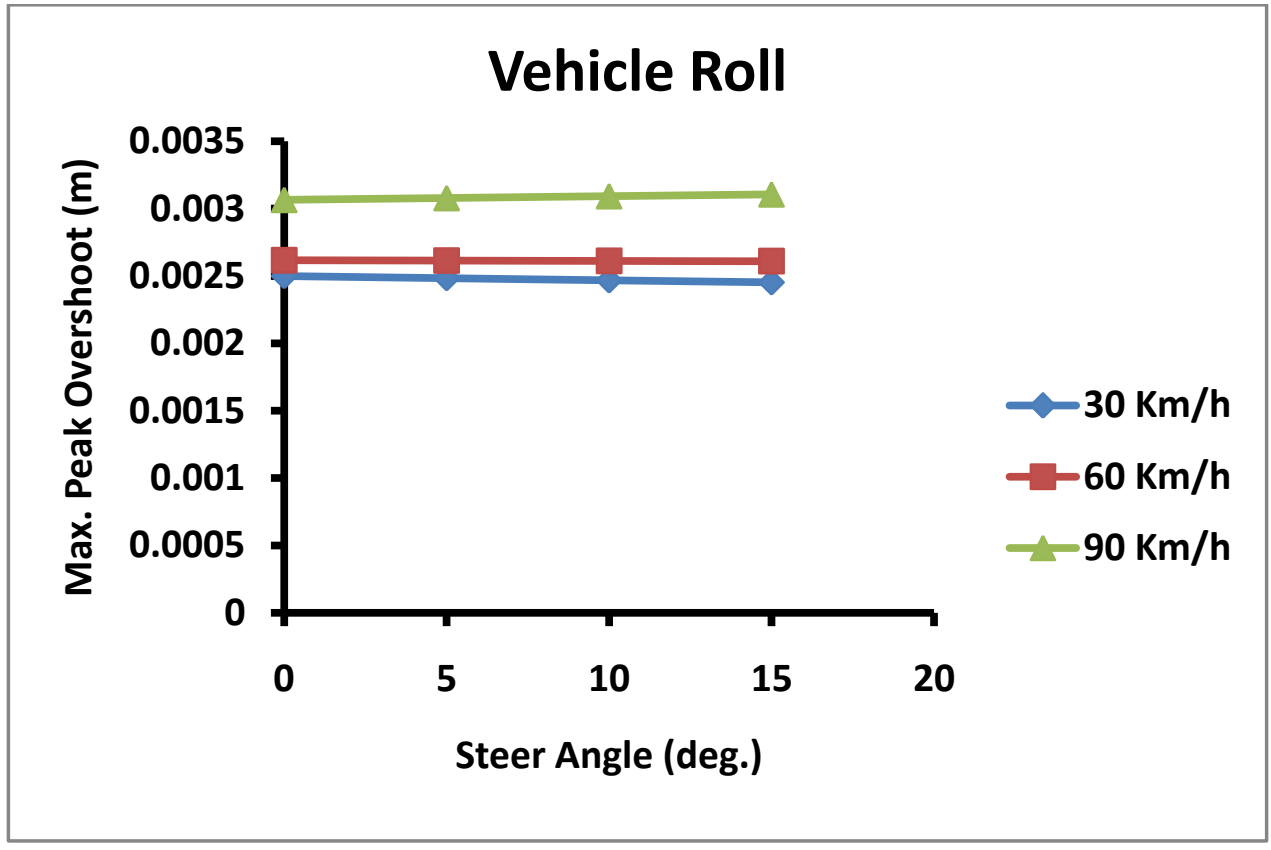

Fig 11: Maximum Peak overshoot analysis for road vehicle roll response subjected to different vehicle speeds and steer angle 


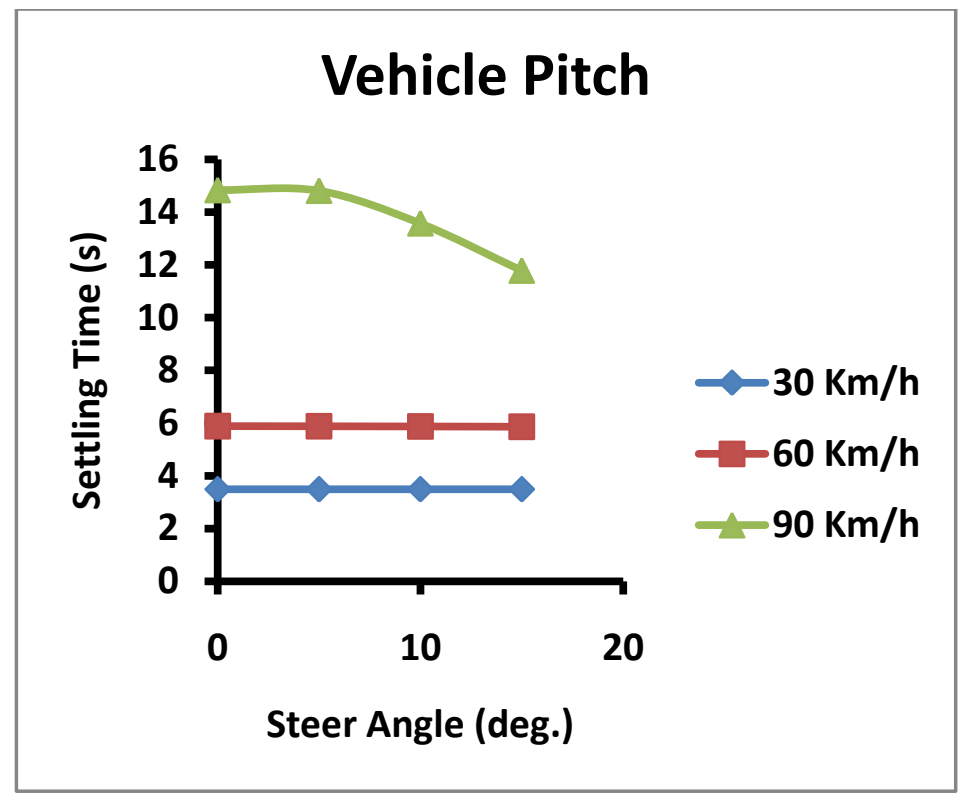

Fig 12: Settling time analysis for road vehicle pitch response subjected to different vehicle speeds and steer angle

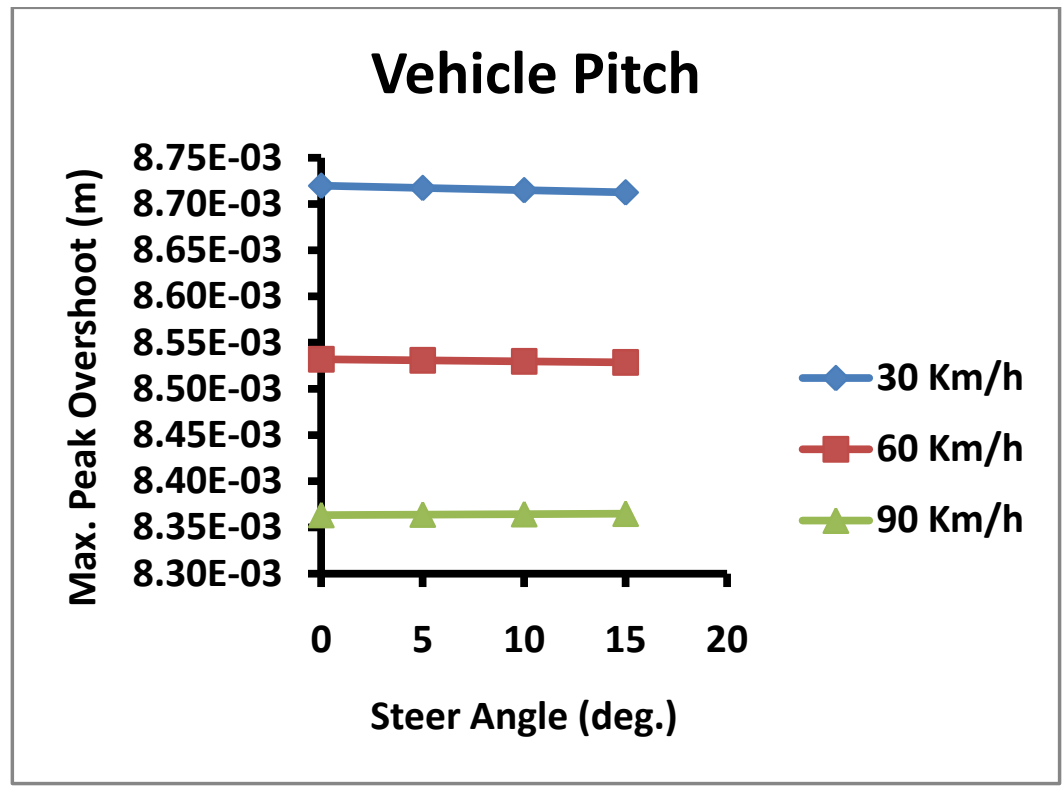

Fig 13: Maximum Peak overshoot analysis for road vehicle pitch response subjected to different vehicle speeds and steer angle

\section{SIMULATION RESULTS WITH SEMI-ACTIVE PID CONTROLLER}

The road vehicle dynamic responses to any external disturbance such as vehicle speeds and sudden step steer angles are improved using a semi-active PID suspension with conical shape spring.

Specifications and variable stiffness of the conical shaped spring are calculated according to dynamic behavior of the road vehicle response according to roll motion. A distinct improvement of dynamic responses for vertical, pitch and roll motions can be achieved as shown in the following figures from the simulation model with semi-active PID suspension controller.
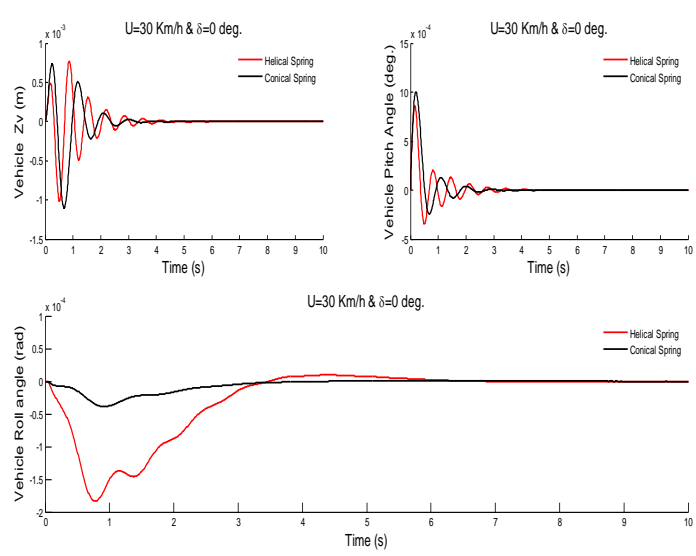

Fig 14: Vertical, pitch and roll responses of road vehicle car body with passive and semi-active PID suspension controller subjected to $(\mathrm{U}=30 \mathrm{~km} / \mathrm{hr} \& \delta=0)$ 

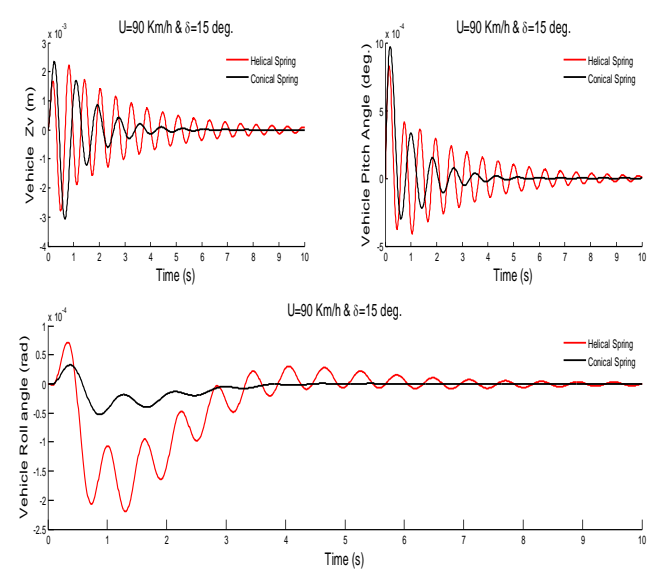

Fig 15: Vertical, pitch and roll responses of road vehicle car body with passive and semi-active PID suspension controller subjected to $(\mathrm{U}=90 \mathrm{~km} / \mathrm{hr} \& \delta=15)$

\section{CONCLUSION}

The simulation results of Vertical, pitch and roll responses of road vehicle car body with semi-active PID suspension shows clear improvement in these responses because the suspension is equipped with conical shaped spring in which the stiffnes is variable and could be changed accordingly. Figure 14 and 15 shows the behavior of vertical, pitch and roll motion for the road vehicles with passive and semi-active PID suspensions subjected to different vehicle speeds and sudden step steer angles. It could be shown clearly that good improvrment is obtained with the roll response in which it indicates that roll response is the most sensitive parameter in dynamic behavior of road vehicle.

\section{REFERENCES}

[1] Ali M. Abd-El-Tawab “ Theoretical and experimental fuzzy control on vehicle pneumatic semi- active suspension system" Journal of American science q(1) pp48-507, 2013

[2] M. Zapateiro et al. " Vibration Control of a class of Semi Active suspension system using neural network and back stepping techniques" Mechanical systems and signal processing 23 pp.1946-1953, 2009

[3] Przemyslaw Gorczyca et. al." Modeling of semi active suspension system" Mechanics and Control Vol.30 No.3 pp.103-108, 2011

[4] M. Senthil Kumar et.al. "analytical and experimental studies on active suspension system of light passenger vehicle to improve the comfort" Mechanika Nr3 (65) pp.34-41, 2007

[5] M.Khairi Aripin et. al. "A yaw Rate Tracking control of Active Front Steering system using composite nonlinear Feedback" Asia Sim, CCIS402, pp. 231-242, 2013

[6] Anil Shirahatt et. al." Optimal Design of Passenger car suspension for ride and road holding" J. of ht Braz. Soc of Mechanical Science Engineering, No.1, pp666-76, 2008

[7] Bushra Rasheed Mohameed "Effect of Bouncing and Pitching on the coupled natural frequency of an Automobile" the Iraqi Journal for Mechanical and Material Engineering, Vol.11, No.3, pp.392-404, 2011.

[8] Soud Farhan Chudhury et.al.”An Approach on Performance comparision between automative passive suspension and active suspension system (PID Controller) Using Matlab Simulink" Journal of Theoretical and Applied Information Technology, Vol.43, No.2, pp.295-300, 2012

[9] Devdutt et.al. "comparative Analysis of Passenger ride Comfort using Various Semi Active Suspension alternatives" International Journal of Recent Advances in Mechanical Engineering (IJMECH), Vol.3, No.3, pp.7989, 2014 